Article

\title{
Effect of Impregnated Inorganic Nanoparticles on the Properties of the Kenaf Bast Fibers
}

Kaiwen Liang ${ }^{1}$, Sheldon Q. Shi ${ }^{1, *}$ and Ge Wang ${ }^{2}$

1 Department of Mechanical and Energy Engineering, University of North Texas, Denton, TX 76207, USA; E-Mail: kaiwen.liang@unt.edu

2 International Center for Bamboo and Rattan, Beijing 100102, China; E-Mail: wangge@icbr.ac.cn

* Author to whom correspondence should be addressed; E-Mail: sheldon.shi@unt.edu; Tel.: +1-940-369-5930; Fax: +1-940-369-8675.

Received: 10 June 2014; in revised form: 16 July 2014 / Accepted: 18 July 2014 /

Published: 22 August 2014

\begin{abstract}
The objective of this research was to evaluate the properties of the chemically retted kenaf bast fiber impregnated with the inorganic nanoparticles. High quality kenaf bast fibers were obtained from a chemical retting process. An in situ inorganic nanoparticle impregnation (INI) process was used to introduce the $\mathrm{CaCO}_{3}$ nanoparticles into the retted kenaf bast fibers. It was found that some of the lignin-based components in the retted fibers were further removed during the INI treatment. From the characterization results, the inorganic nanoparticles $\mathrm{CaCO}_{3}$, with different shapes and sizes, appeared at the surface of the impregnated fiber after treatment. Heterogeneous $\mathrm{CaCO}_{3}$ nanoparticle distribution was observed on the INI treated fibers. The $\mathrm{CaCO}_{3}$ contents were different at different locations along the impregnated fiber. The presence of $\mathrm{CaCO}_{3}$ inorganic nanoparticles at the fiber surface increased the root mean square (RMS) surface roughness by $5.8 \%$ and decreased the hydrophilic nature of the retted fibers, evidenced by a $59.4 \%$ decrease in adhesion force between the fiber and hydrophilic AFM tip. In addition, the impregnation of $\mathrm{CaCO}_{3}$ dramatically increased the Young's modulus of the fiber by $344 \%$.
\end{abstract}

Keywords: kenaf; nanoparticle; impregnation; Atomic Force Microscopy (AFM); X-ray Photoelectron Spectroscopy (XPS); Scanning Electron Microscopy (SEM) 


\section{Introduction}

The lignocellulosic materials are sustainable, environmentally friendly and renewable. The shortage of petroleum and environmental concern has resulted in a considerable increase in the usage of renewable natural resources in recent years. Lignocellulosic natural fibers can be obtained from pulping processes, such as thermal mechanical pulping or chemical pulping. These fibers, processed from wood, kenaf, hemp, jute, sisal, etc., may be used as reinforcements in the polymer composites for both non-structural and structural applications, including but not limited to decking, doors, window frames, flooring, fencing, walls, furniture, automobiles and electronic products $[1,2]$.

Kenaf is a warm season, annual fiber crop. It grows in large amounts every year in the United States. For example, the growth of kenaf was about 2300 acres in 1998, 5600 acres in 1999 and there were as much as 7000 acres of kenaf in 2000 in Texas [3]. It is an underutilized biomass in Texas. Kenaf bast fiber is attractive also due to its high cellulose content and good mechanical properties. The cellulose content of kenaf bast fiber is about $46 \%$ to $57 \%$ [4]. The tensile strength and modulus of a single kenaf fiber can be as high as 11.9 and $60.0 \mathrm{GPa}$, respectively [5,6]. Thus, kenaf bast fiber is an excellent resource for newsprint, bond paper, etc. It is also a good reinforcement candidate for the natural fiber reinforced composites for automotive applications [6-12].

In fabricating thermoplastic polymer composites with the natural fiber reinforcements, the compatibility between the natural fibers and the thermoplastic matrices is a major issue for the natural fiber composites [13-15]. Lignocellulosic natural fibers are hydrophilic, containing strongly polarized hydroxyl groups, which are incompatible with hydrophobic thermoplastics. Fiber pulled out is often observed at the flexural surface of natural fiber reinforced polymer composites [16]. Fiber surface modification, such as plasma treatment can introduce the chemical functional groups, which make natural fiber more compatible with polymer [17,18]. Simultaneously, fiber and polymer matrix breakdown can be observed at the flexural surface of treated natural fiber composites. Second, there are many micropores in the cell wall structure of natural fibers. Additional micropores are created during the chemical treatments or pulping due to the removal of some lignin and hemicellulose of the natural fibers [19]. The presence of these micropores in the cell wall could cause manufacturing defects, such as interfacial failure and air pockets, in the composites.

If the nanoparticles can be introduced onto the fiber surfaces serving as attraction force manipulators to polymer matrixes, the nanoparticles will have a potential to improve the affinity between the natural fiber and the polymer matrix, and thus the physical and mechanical properties of the composites can be enhanced. Therefore, in order to improve the compatibility between natural fibers and thermoplastics and reduce the air pocket defect, micro or nano sized particles can be introduced into the micropores of the fiber cell wall structure through an impregnation process to fill those pores. The nanoparticle impregnation could not only fill the micropores of the fiber cell wall structure minimizing the air bubble defects of the composites, but also introduce the nanoparticles onto the fiber surfaces serving as the affinity sites to improve the compatibility at the fiber and polymer interfaces [20,21].

We have developed an in situ inorganic nanoparticle impregnation (INI) process to obtain high quality kenaf bast fibers [20-22]. The objective of this study is to investigate the effect of impregnated 
inorganic nanoparticles in the kenaf bast fibers on the fiber properties, such as morphology, chemical components, surface roughness and modulus.

\section{Experimental Section}

Materials: In the fiber retting experiments, Kenaf stems (Hibiscus cannabinus, L.) were obtained from Kengro Incorporation, Charleston, MS, USA. After the bast and core were separated using a crushing process, the bast was cut into $5.1 \mathrm{~cm}$ in lengths. The bast was then dried until an $8 \%$ moisture content was achieved. The dried bast was stored in an environment of $22{ }^{\circ} \mathrm{C}$ and $50 \%$ relative humidity. The retting chemicals, such as sodium hydroxide, were in lab grade, and the acetic acid was in regent grade. The inorganic nanoparticle impregnation chemicals, such as sodium carbonate and calcium chloride, were purchased from Thermo Fisher Scientific Inc. (Waltham, MA, USA).

Chemical Retting of Kenaf Fiber: Kenaf bast fibers with about 8\% moisture content were retted with $5 \% \mathrm{NaOH}$ solution (Fiber: $\mathrm{NaOH}=1: 30 \mathrm{~g} / \mathrm{mL}$ ) in a hermetical reactor (Parr Instrument Co., Moline, IL, USA, 251M) for an hour at $160{ }^{\circ} \mathrm{C}$ and $0.6 \mathrm{MPa}$. The retting process was taken under the mechanical stirring. The kenaf fibers after the chemical retting were neutralized with $5 \%$ acetic acid, washed with water to remove excessive chemicals, and then oven dried.

Inorganic Nanoparticle Impregnation of Kenaf Fiber: Two steps of the ionic salt treatment in the heated and pressurized chamber were used for the impregnation process. The fibers were first impregnated with $0.1 \mathrm{~mol} / \mathrm{L} \mathrm{Na}_{2} \mathrm{CO}_{3}$ (primary salt) (Fiber: $\mathrm{Na}_{2} \mathrm{CO}_{3}$ solution $=5: 400, \mathrm{~g} / \mathrm{mL}$ ) in a hermetical reactor with mechanical stirring at $70{ }^{\circ} \mathrm{C}$ and $0.1 \mathrm{MPa}$ for $30 \mathrm{~min}$. Then secondary ionic salt solution, $\mathrm{CaCl}_{2}$, was added into the reactor. The $\mathrm{CaCl}_{2}$ impregnation process was taken place at $160{ }^{\circ} \mathrm{C}$ and $0.7 \mathrm{MPa}$ for $15 \mathrm{~min}$. The molar ratio of $\mathrm{Na}_{2} \mathrm{CO}_{3}: \mathrm{CaCl}_{2}$ was $1: 2$. The primary ionic salt $\left(\mathrm{Na}_{2} \mathrm{CO}_{3}\right)$ reacted with the secondary ionic salt $\left(\mathrm{CaCl}_{2}\right)$ in the fibers to generate $\mathrm{CaCO}_{3}$ nanoparticles in the micropore structure of the fiber cell wall. The nanoparticle crystals may grow out onto the fiber surface from the inner cell wall. The impregnated fibers were washed with distilled water to remove the excess $\mathrm{CaCO}_{3}$ particles and other ions on fiber surface, and then oven dried.

X-ray Photoelectron Spectroscopy (XPS): XPS analysis was performed using a PHI 1600 XPS Electron Scanning Chemical Analysis instrument (Physical Electronics Inc., Chanhassen, MN, USA) with a PHI 10-360 spherical detector. An achromatic Mg K_alpha X-ray source was operated at $300 \mathrm{~W}$ and $15 \mathrm{kV}$. XPS data was collected with PHI surface analysis software version 3.0 and analyzed with CasaXPS analysis software version 2.2.88. High resolution scans were energy referenced to $\mathrm{C}_{1} \mathrm{CH}_{\mathrm{x}}$ environment at $285 \mathrm{eV}$. The specimens were left inside the vacuum chamber for overnight in order to degas them.

Scanning Electron Microscopy (SEM): A JEM2100 field emission scanning electron microscope (FESEM) (JEOL USA Inc., Peabody, MA, USA) was used to study the effects of retting and INI on the morphology of the kenaf fibers. An attached X-ray energy dispersive spectrometer (X-EDS) was used to obtain elemental compositions of $\mathrm{CaCO}_{3}$ nanoparticles in the composites. The SEM samples were coated with gold before SEM measurements. The electron beam spot size used in X-EDS was about $5 \mathrm{~nm}$ in diameter.

Atomic Force Microscopy (AFM): A Bruker Dimension Icon AFM (Bruker Corporation, Camarillo, CA, USA) with ScanAsyst ${ }^{\mathrm{TM}}$ (Bruker, Banner La, UK) was used to image the surface 
topography as well as to determine modulus of the fibers. Images were recorded in the recently released PeakForce QNM (Quantitative NanoMechanics) imaging mode using typical silicon tips (Tap525A, spring constant $200 \mathrm{~N} / \mathrm{m}$, Veeco, Santa Barbara, CA, USA). Imaging was performed under ambient conditions. The PeakForce QNM mode relies on the information available in AFM force-distance curves, and the maximum force applied to the sample by the tip is constant. The deflection of the cantilever at this maximum force leads to topography mapping, the stiffness/modulus is extracted from the slope of the retraction curve near zero separation, and the adhesion pull-off force comes from the minimum in the retraction curve [23]. The image was analyzed using the AFM software (Veeco Instruments, version 6.13).

\section{Results and Discussion}

\subsection{Surface Chemical Composition of the Fibers}

The chemically retted and INI treated kenaf fibers were first examined by XPS. XPS is an analytical technique used to detect the surface composition of the fiber. XPS provides quantitative information on different bonded carbon atoms on the fiber surface besides the chemical composition. The surface composition of the retted and impregnated fibers is shown in Table 1. Carbon $(\sim 285 \mathrm{eV})$ and oxygen $(\sim 533 \mathrm{eV})$ were the main elements detected in the fibers in XPS survey scan. The presence of $\mathrm{CaCO}_{3}$ was evidenced by the calcium characteristic peak (Ca2p) at a binding energy around $350 \mathrm{eV}$. The calcium content in the fiber increased after the INI treatment. Carbon was the dominant element at the surface of these two fibers, while the $\mathrm{O} / \mathrm{C}$ ratio was different. Kenaf fiber is mainly composed of cellulose, hemicellulose, lignin and pectin [24]. Some of the hemicelluloses and lignin were removed from the fibers during the alkali retting treatment. The $\mathrm{O} / \mathrm{C}$ ratio of pure cellulose fibers has been reported to be around 0.8 [25]. In this report, the $\mathrm{O} / \mathrm{C}$ ratio of the chemically retted fiber was obtained as 0.43 , which was very similar to the reported data for alkali treated kenaf fiber [26]. After the INI treatment, the $\mathrm{O} / \mathrm{C}$ ratio the fiber was raised to 0.59 . Thus, the oxygen rich cellulose component increased at the fiber surface after the $\mathrm{CaCO}_{3}$ nanoparticle impregnation treatment of the retted fiber.

Table 1. Surface composition of inorganic nanoparticle impregnated (INI) kenaf bast fibers with chemically retted fibers used as control.

\begin{tabular}{cccccc}
\hline \multirow{2}{*}{ Sample } & \multicolumn{5}{c}{ Surface composition (\%) } \\
\cline { 2 - 6 } & $\mathbf{O}$ & $\mathbf{C}$ & $\mathbf{N}$ & $\mathbf{C a}$ & $\mathbf{O} / \mathbf{C}$ \\
\hline Retted fiber & 27.72 & 64.79 & 7.47 & 0.22 & 0.43 \\
Impregnated fiber & 33.73 & 57.37 & 7.49 & 1.41 & 0.59 \\
\hline
\end{tabular}

Figure 1 is the deconvoluted high resolution C 1s XPS spectra which details the analysis of the fiber composition. The chemical shifts of carbon $(\mathrm{C} 1 \mathrm{~s})$ in cellulose includes $\mathrm{C}-\mathrm{C}-\mathrm{OH}, \mathrm{C}-\mathrm{OH}, \mathrm{C}-\mathrm{OR}$, and $\mathrm{O}-\mathrm{C}-\mathrm{O}$, and those of lignin are mainly $\mathrm{CH}_{\mathrm{x}}$ and $\mathrm{C}-\mathrm{OR}[25,27]$. A new peak $\mathrm{C} 5$ in deconvoluted C 1s XPS high resolution spectra of impregnated kenaf fibers (Figure 1b) appeared from inorganic carbonates $\left(\mathrm{CO}_{3}{ }^{2-}\right)$ [28] introduced from the $\mathrm{CaCO}_{3}$ nanoparticle impregnation treatment of retted fibers. Table 2 summarizes the deconvoluted C 1s XPS high resolution spectra peaks assigned to the corresponds functional groups with the correlative data. After the $\mathrm{CaCO}_{3}$ nanoparticle impregnation 
treatment of the retted fibers, the intensity of component peak $\mathrm{C} 1$ which corresponding to $\mathrm{C}-\mathrm{C}$ and $\mathrm{C}-\mathrm{H}$ chemical groups decreased significantely. In contrast, the content of $\mathrm{O}-\mathrm{C}-\mathrm{O}$ and $\mathrm{O}-\mathrm{C}=\mathrm{O}$ chemical groups increased by $47 \%$ and $65 \%$, respectively. The inorganic carbonates $\left(\mathrm{CO}_{3}{ }^{2-}\right)$ componet peak appeared and the content of calcium increased (Table 1) after the treatment. The impregnated fibers were washed with distilled water to remove the excess $\mathrm{CaCO}_{3}$ particles and other ions on the fiber surface, and then oven dried. The carbonate from the $\mathrm{Na}_{2} \mathrm{CO}_{3}$ can be neglected. The EDX results (Table 3) also confirmed that neither sodium $(\mathrm{Na})$ nor chlorine $(\mathrm{Cl})$ was detected. Thus, the carbonate can only exist in $\mathrm{CaCO}_{3}$. The $\mathrm{CaCO}_{3}$ inorganic nanoparticles were successfully generated at the surface of the impregnated fiber after the treatment. Also, additional lignin-based components were further removed from the retted fiber during the INI treatment process. This might be caused by the additional hot water extraction under the high temperature and pressure $\left(160{ }^{\circ} \mathrm{C}\right.$ and $0.7 \mathrm{MPa}$ for $15 \mathrm{~min}$ ) during the INI treatment.

Figure 1. Deconvoluted C 1s XPS high resolution spectra of (a) chemically retted; and (b) inorganic nanoparticle impregnated kenaf bast fibers.
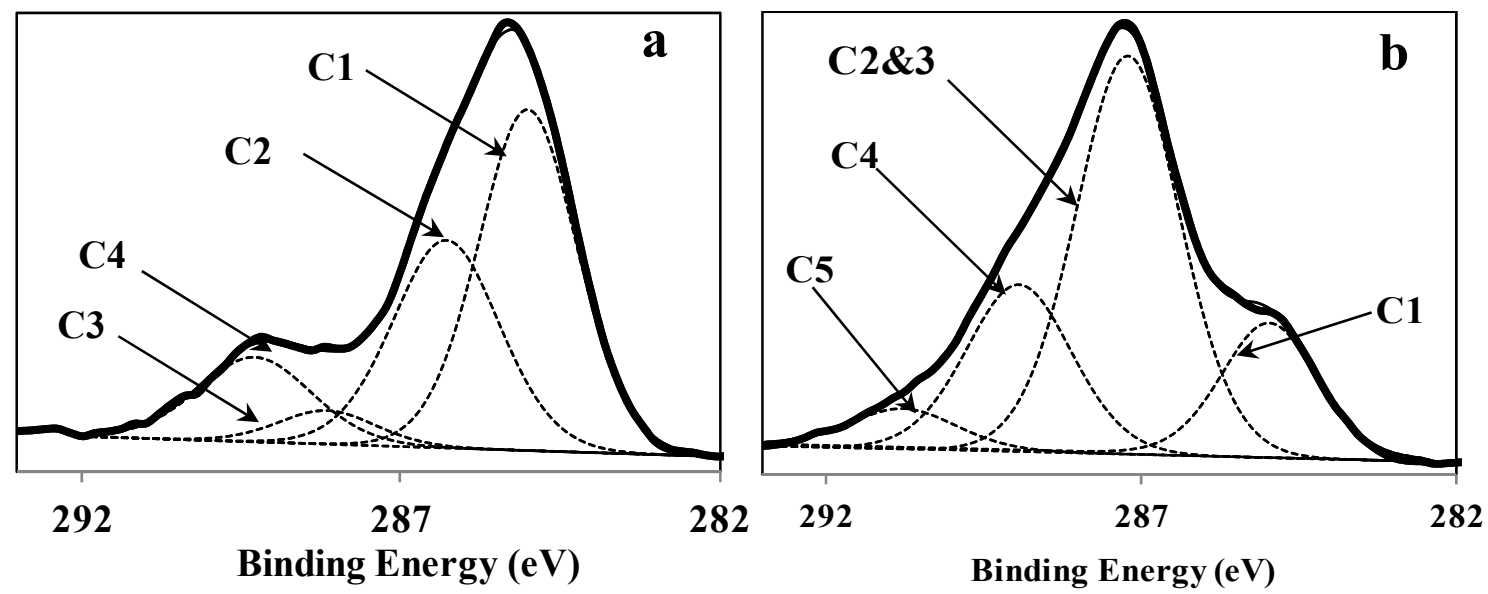

Table 2. C 1s component intensities of INI kenaf bast fibers with the chemically retted fibers used as control.

\begin{tabular}{cccccc}
\hline Item & $\mathbf{C 1}(\mathbf{C}-\mathbf{C}, \mathbf{C}-\mathbf{H})$ & $\mathbf{C 2}(\mathbf{C}-\mathbf{O})$ & $\mathbf{C 3}(\mathbf{O}-\mathbf{C}-\mathbf{O})$ & $\mathbf{C 4}(\mathbf{O}-\mathbf{C}=\mathbf{O})$ & $\mathbf{C 5 ~ C O}_{\mathbf{3}}{ }^{2-}$ \\
\hline Bindingenergy $(\mathrm{eV})$ & 285 & 286.5 & 288.1 & 289 & 290.8 \\
Retted fiber & $48.73 \%$ & $32.35 \%$ & $4.79 \%$ & $14.13 \%$ & 0 \\
Impregnated fiber & $16.69 \%$ & \multicolumn{2}{c}{$54.58 \%$} & $23.25 \%$ & $5.47 \%$ \\
\hline
\end{tabular}

Table 3. X-ray EDS spectra data of INI kenaf bast fibers.

\begin{tabular}{ccccc}
\hline Spectrum & Element & $\mathbf{w t} \%$ & $\mathbf{a t} \%$ & $\mathbf{C a C O}_{\mathbf{3}} \mathbf{w t} \%$ \\
\hline \multirow{4}{*}{1} & $\mathrm{O}$ & 36.81 & 33.72 & $\mathrm{NA}$ \\
& $\mathrm{C}$ & 42.50 & 51.86 & $\mathrm{NA}$ \\
& $\mathrm{N}$ & 10.02 & 10.48 & $\mathrm{NA}$ \\
& $\mathrm{Ca}$ & 10.52 & 3.85 & 26.27 \\
\hline
\end{tabular}


Table 3. Cont.

\begin{tabular}{|c|c|c|c|c|}
\hline Spectrum & Element & wt\% & at\% & $\mathrm{CaCO}_{3} \mathrm{wt}^{2}$ \\
\hline \multirow{4}{*}{2} & $\mathrm{O}$ & 56.57 & 62.48 & NA \\
\hline & $\mathrm{C}$ & 17.74 & 26.11 & NA \\
\hline & $\mathrm{N}$ & NA & NA & NA \\
\hline & $\mathrm{Ca}$ & 25.41 & 11.21 & 63.46 \\
\hline \multirow{4}{*}{3} & $\mathrm{O}$ & 34.07 & 29.50 & NA \\
\hline & $\mathrm{C}$ & 51.33 & 59.22 & NA \\
\hline & $\mathrm{N}$ & 9.56 & 9.46 & NA \\
\hline & $\mathrm{Ca}$ & 4.65 & 1.61 & 11.61 \\
\hline \multirow{4}{*}{4} & $\mathrm{O}$ & 25.46 & 20.95 & NA \\
\hline & $\mathrm{C}$ & 62.26 & 68.24 & NA \\
\hline & $\mathrm{N}$ & 11.09 & 10.42 & NA \\
\hline & $\mathrm{Ca}$ & 1.19 & 0.39 & 2.97 \\
\hline \multirow{4}{*}{5} & $\mathrm{O}$ & 26.08 & 21.87 & NA \\
\hline & $\mathrm{C}$ & 58.58 & 65.42 & NA \\
\hline & $\mathrm{N}$ & 11.83 & 11.33 & NA \\
\hline & $\mathrm{Ca}$ & 2.28 & 0.76 & 5.69 \\
\hline \multirow{4}{*}{6} & $\mathrm{O}$ & 26.39 & 22.18 & NA \\
\hline & $\mathrm{C}$ & 58.43 & 65.41 & NA \\
\hline & $\mathrm{N}$ & 11.61 & 11.15 & NA \\
\hline & $\mathrm{Ca}$ & 3.26 & 1.09 & 8.14 \\
\hline
\end{tabular}

\subsection{Scanning Electron Microscopy (SEM) of the Fibers}

Figure 2 shows the SEM micrographs of the chemically retted and INI treated kenaf fibers. There were some residues or impurities left between the fibers, which could not be removed by alkali chemical retting treatment (Figure 2a). In contrast, much less residues were observed between the fibers after the INI treatment. Some of the kenaf fiber components may be further removed during the high temperature treatment, such as at $160{ }^{\circ} \mathrm{C}$. There was a large amount of inorganic particles at the surface of the impregnated fiber (Figure $2 \mathrm{~b}$ ) and some particles grow from inside of the fibers to the outer surface (Figure 2d). Figure 3 in higher magnification shows that $\mathrm{CaCO}_{3}$ particles were generated from inside of the fiber cell wall onto the outer surface of the fiber. The inorganic particles were in different shapes. Some were square, and the others were spherical. The particle sizes showed a wide distribution ranging from $80 \mathrm{~nm}$ to $6 \mu \mathrm{m}$. The surface of the impregnated fiber (Figure 2d) was rougher than that of the retted fiber (Figure 2c).

Figure 3 displays one sample SEM micrograph of the INI treated kenaf fiber. Table 3 summarizes the corresponding X-ray EDS elemental analysis of this fiber at the locations shown in Figure 3. It was clearly seen that $\mathrm{CaCO}_{3}$ have generated from inside of the fiber cell wall onto the outer surface of the fiber, and shape of the particles is approximately rectangular. The numbers shown on the SEM micrographs refer to the EDS spectrum number represented in Figure 3. The heads of the arrows are located where the X-ray beams impinged on the sample. The spot sizes of the impinged X-ray beams were around $5 \mathrm{~nm}$ diameter and small relative to the feature sizes observed in the SEMs. All of the regions studied exhibited the presence of $\mathrm{CaCO}_{3}$ as indicated by the value of the $\mathrm{Ca}$ content. Pure 
$\mathrm{CaCO}_{3}$ contains $40.04 \mathrm{wt} \%$ and 20 at $\% \mathrm{Ca}$. The highest $\mathrm{Ca}$ content exhibited by EDS spectrum 2 (Figure 3 ) contained only $25.41 \mathrm{wt} \%$ (11.21 atom \%) Ca indicating that the region with $\mathrm{CaCO}_{3}$ particles also contained substantial amounts of cellulose material. This was further confirmed by the nitrogen content in spectrum 1 (Table 3). Also, the weight percentages of $\mathrm{CaCO}_{3}$ were different from point to point within the same $\mathrm{CaCO}_{3}$ particle domain. No particle was observed at the spectrum 3 to 6 of the impregnated fiber. However, significant $\mathrm{Ca}$ signal was still detected, implying that some $\mathrm{CaCO}_{3}$ was molecularly incorporated into the fiber cell wall. As discussed above, since neither sodium (Na) nor chlorine $(\mathrm{Cl})$ was detected from the EDX, the calcium can only exist in $\mathrm{CaCO}_{3}$. The contents of $\mathrm{CaCO}_{3}$ were also different from point to point along the impregnated fiber. The $\mathrm{CaCO}_{3}$ nanoparticles with different shapes and sizes appeared at the surface of the impregnated fiber after the INI treatment. Heterogeneous $\mathrm{CaCO}_{3}$ nanoparticle distribution was observed on the INI treated fibers.

Figure 2. Scanning electron micrographs (SEMs) of the (a) $300 \times \&$ (c) $5000 \times$ chemically retted; and (b) $500 \times \&$ (d) $8000 \times$ inorganic nanoparticle impregnated kenaf bast fibers.
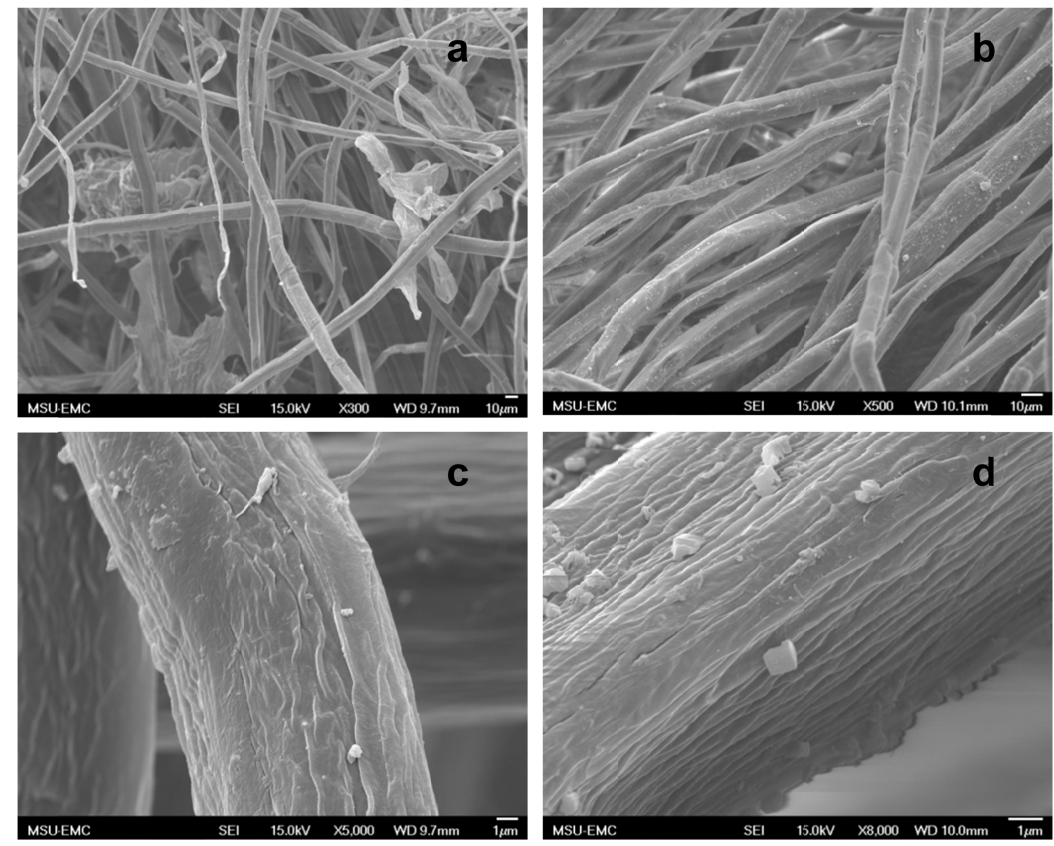

Figure 3. Scanning electron micrograph (SEM) of the inorganic nanoparticle impregnated kenaf fibers.

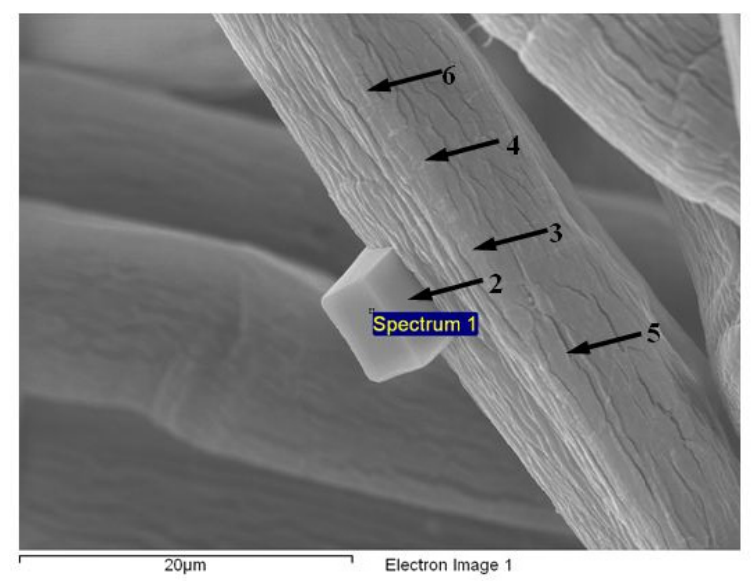




\subsection{Atomic Force Microscopy (AFM) of the Fibers}

The characterization of the chemically retted and INI treated kenaf bast fibers was also carried out with the AFM under the ambient environment. The sample size was $2 \mathrm{~mm}^{2}$ of the fiber bundle. Each fiber bundle is composed of many single fibers and 10 spots on the fiber of each treatment were measured. Root mean square surface roughness, image mean average adhesion and Derjaguin-Müller-Toporon (DMT) Young's modulus of the chemically retted and INI treated kenaf bast fibers are summarized Table 4.

Table 4. Root mean square surface roughness, image mean average adhesion and Derjaguin-Müller-Toporon (DMT) Young's modulus of INI kenaf bast fibers with chemically retted fibers used as control.

\begin{tabular}{cccc}
\hline \multirow{2}{*}{ Sample } & \multirow{2}{*}{$\begin{array}{c}\text { Root mean squaresurface } \\
\text { roughness (Nm) }\end{array}$} & \multicolumn{2}{c}{ Image mean average } \\
\cline { 3 - 4 } & 155 & 387 & Adhesionn (N) \\
Retted fiber & 164 & 157 & 120 \\
Impregnated fiber & & DMT modulus (GPa) \\
\hline
\end{tabular}

Figure 4 shows the AFM height and peak force error images $\left(25 \mu \mathrm{m}^{2}\right)$ of chemically retted and inorganic nanoparticle impregnated kenaf fibers. The root mean square (RMS) roughness was used to quantify the surface roughness. Height variations from an average height were used to calculate the RMS roughness. The RMS surface roughness of the chemically retted and INI treated kenaf fibers were 155 and $164 \mathrm{~nm}$, respectively. The roughness of the impregnated fiber was higher than that of retted fiber. This may be due to a large amount of nano and micro size $\mathrm{CaCO}_{3}$ inorganic particles generated at the surface of the impregnated fiber as shown in Figure 2d. The increased fiber surface roughness would be favorable for the improvement of fiber surface specific area, inter fiber friction and bonding [29].

Figure 5 shows the AFM adhesion images $\left(25 \mu \mathrm{m}^{2}\right)$ of the chemically retted and INI treated kenaf fibers. The bright areas correspond to the higher adhesion forces between the tip and fiber, while the dark areas correspond to weaker adhesion forces. There were several big brighter areas in the AFM adhesion image of retted fiber. The distribution of adhesion forces on the surface of impregnated fiber was more homogeneous than that of retted fiber. The image-mean average adhesion of the chemically retted and INI treated kenaf fibers were 387 and $157 \mathrm{nN}$, respectively. The adhesion force between the fiber and AFM tip decreased after the INI treatment. Some of the adhering components of the retted fiber might be removed during the INI treatment. Under the ambient environment and without chemical bonding forces, the adhesion force between AFM tip and the sample surface is the sum of van der Waals and capillary forces [30]. In the fiber-fiber contact, the capillary force would be the major contribution to the adhesion force owning to its hydrophilic nature [31]. Condensation of water from the environment resulted in the formation of capillary bridge between the tip and fiber during contact, and contributed to the origin of capillary force. Capillary condensation occurred easily on a hydrophilic surface such as the surface of natural fiber [32]. 
Figure 4. Atomic Force Microscopy (AFM) height and peak force error images $\left(25 \mu \mathrm{m}^{2}\right)$ of $(\mathbf{a}, \mathbf{c})$ chemically retted and $(\mathbf{b}, \mathbf{d})$ inorganic nanoparticle impregnated kenaf fibers.

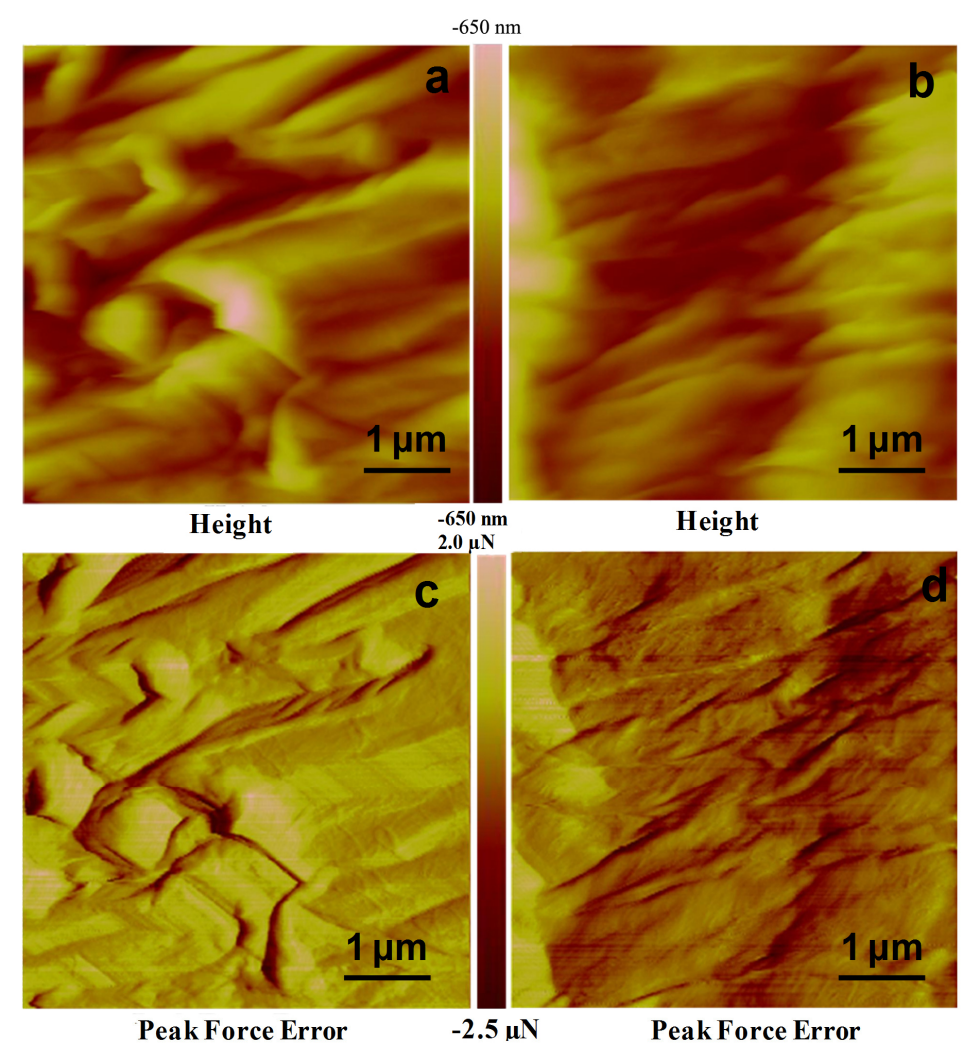

Adhesion is also dependent on the contact area between the fiber and the tip. Thus, the topographic height image of the fiber surface is important in the interpretation of adhesion image. The contact area between the fiber and the tip increases as the fiber surface roughness increases, which would increase the adhesion measured. The generation of $\mathrm{CaCO}_{3}$ inorganic nanoparticles at the fiber surface increased the RMS surface roughness by $5.8 \%$. It was also shown that the adhesion of the impregnated fiber decreased by $59.4 \%$. Thus, the presence of $\mathrm{CaCO}_{3}$ inorganic nanoparticles at the fiber surface decreased the affinity between the fiber and hydrophilic silicon nitride AFM tip. This indicated that the presence of $\mathrm{CaCO}_{3}$ inorganic nanoparticles at the fiber surface somewhat decreased the hydrophilic nature of the fiber.

The cellulose chains are composed of amorphous and crystalline regions, together with some hemicelluloses, lignin and pectin. Removing the hemicelluloses, lignin and pectin, and reducing the amorphous regions can effectively increase the cellulose content and the percentage of crystalline regions of the cellulosic fibers, so that the fibers will have a much higher strength property [33]. Figure 6 shows the AFM modulus images $\left(25 \mu \mathrm{m}^{2}\right)$ of chemically retted and INI treated kenaf fibers. The image mean average modulus of the chemically retted and INI treated kenaf fibers were 27 and $120 \mathrm{GPa}$, respectively. The modulus of fiber increased by $344 \%$ by incorporating $\mathrm{CaCO}_{3}$ inorganic nanoparticles into the fiber. Young's and bulk modulus of $\mathrm{CaCO}_{3}$ can be as high as 88 and $130 \mathrm{GPa}$, respectively [34]. Removing lignin-based components from retted fiber, the successful incorporation of inorganic nanoparticles $\mathrm{CaCO}_{3}$ into the cell wall of the fiber during the INI treatment, and synergistic effect of the fiber and $\mathrm{CaCO}_{3}$ inorganic nanoparticles contributed to the dramatic increase in the modulus of the impregnated fiber. 
Figure 5. AFM adhesion images $\left(25 \mu \mathrm{m}^{2}\right)$ of (a) chemically retted; and (b) inorganic nanoparticle impregnated kenaf fibers. Numerical values in each image across the sections indicated by the line in (a) and (b) are given below the images.
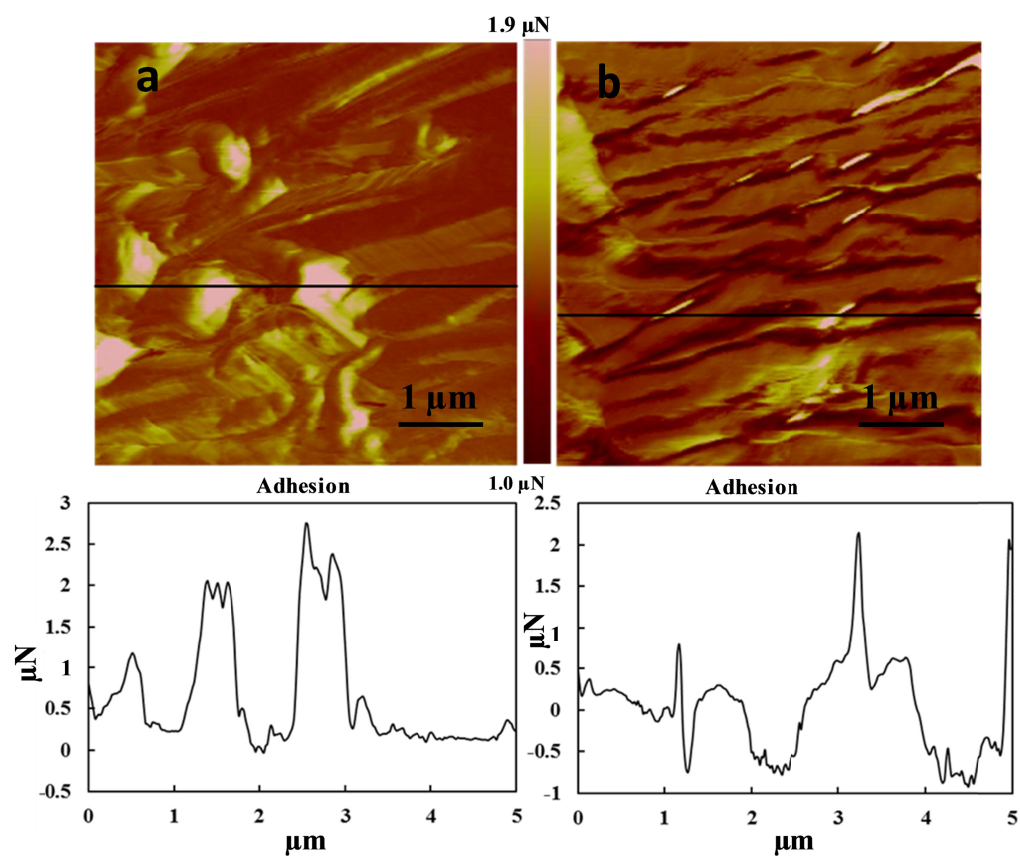

Figure 6. AFM modulus images $\left(25 \mu \mathrm{m}^{2}\right)$ of (a) chemically retted; and (b) inorganic nanoparticle impregnated kenaf fibers. Numerical values in each image across the sections indicated by the line in (a) and (b) are given below the images.
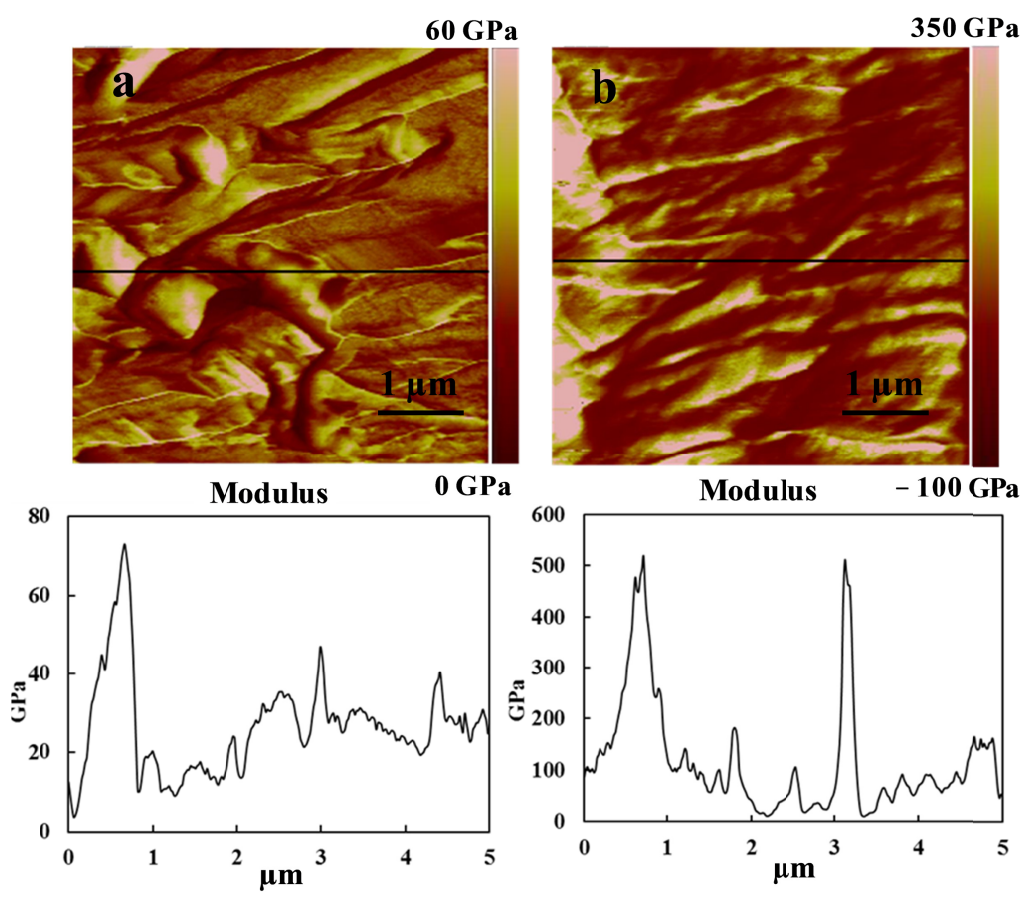

\section{Conclusions}

High quality kenaf bast fibers were obtained from a chemical retting process and then impregnated from an in situ inorganic nanoparticle impregnation process. XPS was used to study the surface 
chemical composition of the fibers. It showed that some of the lignin-based components were further removed from retted fiber during the INI treatment. The inorganic $\mathrm{CaCO}_{3}$ nanoparticles appeared at the surface of the impregnated fiber after treatment. The inorganic particles were in different shapes and sizes ranging from $80 \mathrm{~nm}$ to $6 \mu \mathrm{m}$ as shown in SEM micrographs. The contents of $\mathrm{CaCO}_{3}$ were also different from point to point along the impregnated fiber as indicated by X-EDS study.

Root mean square surface roughness, image-mean average adhesion and DMT modulus of the chemically retted and INI treated kenaf fibers were studied by the AFM under ambient environment. The presence of $\mathrm{CaCO}_{3}$ inorganic nanoparticles at the fiber surface slightly increased root mean square (RMS) surface roughness by $5.8 \%$, and decreased the hydrophilic nature as evidenced by a $59.4 \%$ decrease in adhesion force between the fiber and the hydrophilic ATM tip. The successful incorporation of inorganic $\mathrm{CaCO}_{3}$ nanoparticles into the fiber cell wall during the INI treatment, and synergistic effect of the fiber and inorganic nanoparticles $\mathrm{CaCO}_{3}$ dramatically increased the Young's modulus of the fiber by $344 \%$.

\section{Acknowledgments}

The research work presented in this paper is supported by National Science Foundation (NSF) under grant numbers CMMI 1247008 and MRI 1126743.

\section{Author Contributions}

Kaiwen Liang did the detailed experiments and the draft writing of the manuscript. Sheldon Q. Shi is the corresponding author to initiate the project, and finalize the manuscript for submission. Ge Wang was involved some discussions on the work described in the manuscript.

\section{Conflicts of Interest}

The authors declare no conflict of interest.

\section{References}

1. Clemons, C. Wood-plastic composites in the United States: The interfacing of two industries. For. Prod. J. 2002, 6, 10-18.

2. Serizawa, S.; Inoue, K.; Iji, M. Kenaf-fiber-reinforced poly(lactic acid) used for electronic products. J. Appl. Polym. Sci. 2006, 100, 618-624.

3. Rymsza, T. Advancements of kenaf in the USA kenaf paper and nonpaper developments. Available online: http://www.visionpaper.com/PDF_speeches_papers/007anwpp.pdf (accessed on 28 May 2012).

4. Han, J.S. Properties of Nonwood Fibers. In Proceedings of the Korean Society of Wood Science and Technology Annual Meeting, Seoul, Korea, 24-25 April 1998; pp. 3-12.

5. Bolton, A.J. Natural fibers for plastic reinforcement. Mater. Tech. 1994, 9, 12.

6. Karnani, R.; Krishnan, M.; Narayan, R. Biofiber-reinforced polypropylene composites. Polym. Eng. Sci. 1997, 2, 476-483. 
7. Rana, A.K.; Mandal, A.; Mitra, B.C.; Jacobson, R.; Rowell, R.; Banerjee, A.N. Short jute fiber-reinforced polypropylene composites: Effect of compatibilizer. J. Appl. Polym. Sci. 1998, 69, 329-338.

8. Eichhorn, S.J.; Baillie, C.A.; Zafeiropoulos, N.; Mwaikambo, L.Y.; Ansell, M.P.; Dufresne, A.; Entwistle, K.M.; Herrera-Franco, P.J.; Escamilla, G.C.; Groom, L.; et al. Review: Current international research into cellulosic fibres and composites. J. Mater. Sci. 2001, 36, 2107-2131.

9. Sanadi, A.R.; Hunt, J.F.; Caulfield, D.F.; Kovacsvolgyi, G.; Destree, B. High Fiber-Low Matrix Composites: Kenaf Fiber/Polypropylene. In Proceedings of 6th International Conference on Woodfiber-Plastic Composites, Madison, WI, USA, 23-25 May 2002; pp. 121-124.

10. Joseph, K.; Thomas, S.; Pavithran, C.; Brahmakumar, M. Tensile properties of short sisal fiber-reinforced polyethylene composites. J. Appl. Polym. Sci. 1993, 47, 1731-1739.

11. Joseph, P.V.; Joseph, K.; Thomas, S.; Pillai, C.K.S.; Prasad, V.S.; Groeninckx, G.; Sarkissova, M. The thermal and crystallisation studies of short sisal fibre reinforced polypropylene composites. Compos. Part A Appl. Sci. Manuf. 2003, 34, 253-266.

12. Tajvidi, M.; Falk, R.H.; Hermanson, J.C. Time-temperature superposition principle applied to a kenaf-fiber/high-density polyethylene composite. J. Appl. Polym. Sci. 2005, 97, 1995-2004.

13. Espert, A.; Camacho, W.; Karlson, S. Thermal and thermomechanical properties of biocomposites made from modified recycled cellulose and recycled polypropylene. J. Appl. Polym. Sci. 2003, 89, 2353-2360.

14. Espert, A.; Vilaplana, F.; Karlsson, S. Comparison of water absorption in natural cellulosic fibres from wood and one-year crops in polypropylene composites and its influence on their mechanical properties. Compos. Part A Appl. Sci. Manuf. 2004, 35, 1267-1276.

15. Ma, C.G.; Rong, M.Z.; Zhang, M.Q.; Friedrich, K. Irradiation-induced surface graft polymerization onto calcium carbonate nanoparticles and its toughening effects on polypropylene composites. Polym. Eng. Sci. 2005, 45, 529-538.

16. Rout, J.; Misra, M.; Tripathy, S.S.; Nayak, S.K.; Mohanty, A.K. The influence of fibre treatment on the performance of coir-polyester composites. Compos. Sci. Technol. 2001, 61, 1303-1310.

17. Yuan, X.; Jayaraman, K.; Bhattacharyya, D. Effects of plasma treatment in enhancing the performance of woodfibre-polypropylene composites. Compos. Part A Appl. Sci. Manuf. 2004, 35, 1363-1374.

18. Kalia, S.; Kaith, B.S.; Kaur, I. Pretreatments of natural fibers and their application as reinforcing material in polymer composites-A review. Polym. Eng. Sci. 2009, 49, 1253-1272.

19. Allan, G.G.; Carroll, J.P.; Negri, A.R.; Raghuraman, M.; Ritzenthaler, P.; Yahiaoui, A. The microporosity of pulp: the precipitation of inorganic fillers within the micropores of the cell wall. Tappi. J. 1992, 75, 175-178.

20. Shi, J.; Shi, S.Q.; Barnes, H.M.; Horstemeyer, M.; Wang, G. Kenaf bast fibers-Part II: Inorganic nanoparticle impregnation for polymer composites. Int. J. Polym. Sci. 2011, 2011, 736474, doi:10.1155/2011/736474.

21. Shi, S.Q.; Lee, S.; Horstemeyer, M. Natural Fiber Retting and Inorganic Nanoparticle Impregnation Treatment for Natural Fiber/Polymer Composites. In Proceedings of the American Society for Composites, University of Washington, Seattle, WA, USA, 19 September 2007. 
22. Lee, S.; Shi, S.Q.; Barnes, M.H. Multifunctional Nanoparticles at the Hydrophilic and Hydrophobic Interface. In Proceedings of Advanced Biomass Science and Technology for Bio-Based Products, Chinese Academy of Forestry, Beijing, China, 23-25 May 2009; pp. 173-181.

23. Cranston, E.D.; Eita, M.; Johansson, E.; Netrval, J.; Salajková, M.; Arwin, H.; Wågberg, L. Determination of Young's modulus for nanofibrillated cellulose multilayer thin films using buckling mechanics. Biomacromolecules 2011, 12, 961-969.

24. John, M.J.; Thomas, S. Biofibres and biocomposites. Carbohydr. Polym. 2008, 71, 343-364.

25. Pommet, M.; Juntaro, J.; Heng, J.Y.Y.; Mantalaris, A.; Lee, A.F.; Wilson, K.; Kalinka, G.; Shaffer, M.S.P.; Bismarck, A. Surface modification of natural fibers using bacteria: Depositing bacterial cellulose onto natural fibers to create hierarchical fiber reinforced nanocomposites. Biomacromolecules 2008, 9, 1643-1651.

26. Sgriccia, N.; Hawley, M.C.; Misra, M. Characterization of natural fiber surfaces and natural fiber composites. Compos. Part A Appl. Sci. Manuf. 2008, 39, 1632-1637.

27. Csiszár, E.; Fekete, E. Microstructure and surface properties of fibrous and ground cellulosic substrates. Langmuir 2011, 27, 8444-8450.

28. Pothan, L.A.; Simon, S.S.; Thomas, S. XPS studies of chemically modified banana fibers. Biomacromolecules 2006, 7, 892-898.

29. Koinkar, V.N.; Bhushan, B. Effect of scan size and surface roughness on microscale friction measurements. J. Appl. Phys. 1997 81, 2472-2479.

30. Butt, H.J.; Cappella, B.; Kappl, M. Force measurements with the atomic force microscope: Technique, interpretation and applications. Surf. Sci. Rep. 2005, 59, 1-152.

31. Bhushan, B.; Sundararajan, S. Micro/nanoscale friction and wear mechanisms of thin films using atomic force and friction force microscopy. Acta Mater. 1998, 46, 3793-3804.

32. Sedin, D.L.; Rowlen, K.L. Adhesion forces measured by atomic force microscopy in humid air. Anal. Chem. 2000, 72, 2183-2189.

33. Shi, J.; Shi, S.Q.; Barnes, H.M.; Pittman, C.U. A chemical process for preparing cellulosic fibers hierarchically from kenaf bast fibers. BioResources 2011, 6, 879-890.

34. Materials data from Crystan Ltd. Poole. UK. Calcite $\left(\mathrm{CaCO}_{3}\right)$ Data Sheet. Available online: http://www.crystran.co.uk/uploads/files/106.pdf (accessed on 18 August 2011).

(C) 2014 by the authors; licensee MDPI, Basel, Switzerland. This article is an open access article distributed under the terms and conditions of the Creative Commons Attribution license (http://creativecommons.org/licenses/by/3.0/). 